

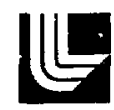

\section{LAWRENCE LVERMORE LABORATOFY}

University of Caltania/Livermore,California/94550

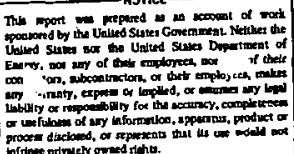

UCRL.52426

\section{FEASIBILITY STUDY FOR COMPUTERIZED AUTOMATION OF EPA REGION II TECHNICAL SUPPORT BRANCH}

Fred B. Stephens, William F. Morris, George W. Barton, Jr., and Eugene R. Fisher

MS date: February 9, 1978 


\section{CONTENTS}

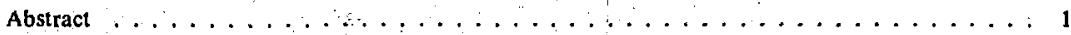

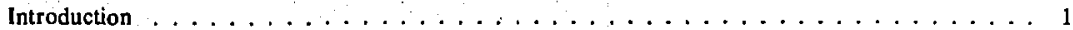

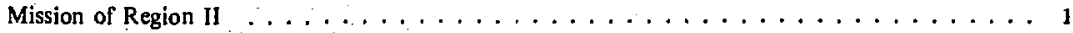

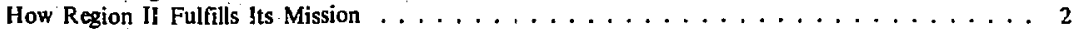

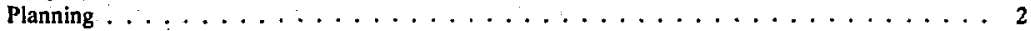

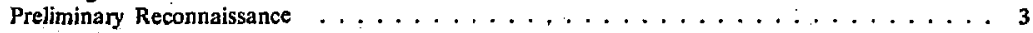

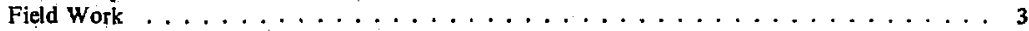

Liboratory Work, Data, and Reports ..................... 3

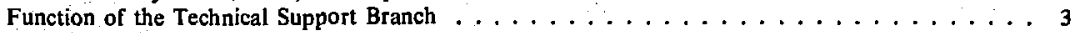

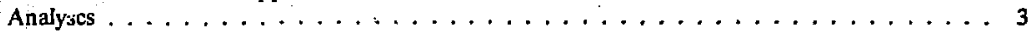

Division of Responsibility ... . . . . . . . . . . . . . . . . 4

Information and Data Flow, Chain of Custody, Records, and Reports . . . . . . . . . . . 4

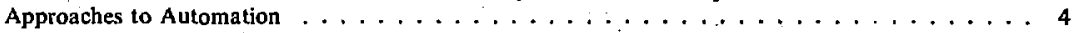

Scope and Constraints ......................... 4

Goals of the Technical Support Branch .................... 5

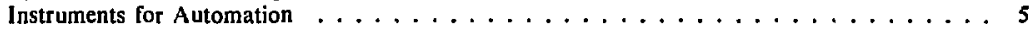

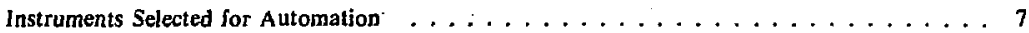

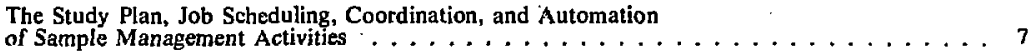

Proposed Systems for Fulfilling the Requirements of the Technical

Suppart Branch Lahoratory . . . . . . . . . . . . . . . . . . . . . . 9

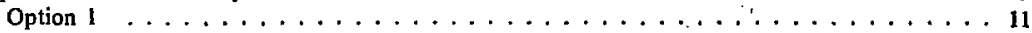

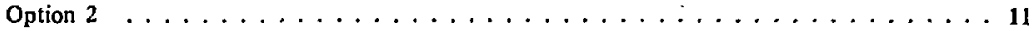

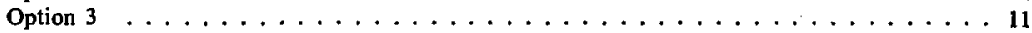

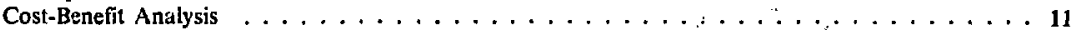

Introduction $\ldots \ldots \ldots \ldots \ldots \ldots \ldots \ldots \ldots \ldots \ldots$

Basis for the Analysis ............................

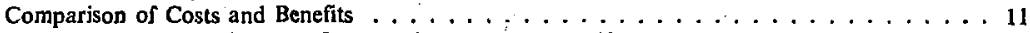

Costs and Benefits Relative to Payout Time and System Life . . . . . . . . . . . 13

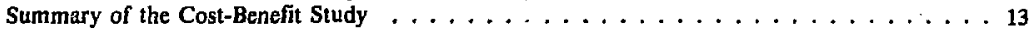

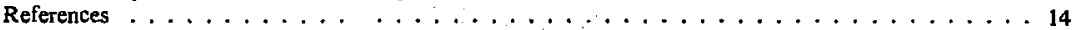

Appendix A. Description of the Proposed Optional Autoniation Systems . . . . . . . . . 15

Option 1: Standard EPA Automation Systenı - Data General Computer . . . . . . . . . . 15

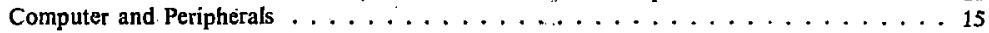

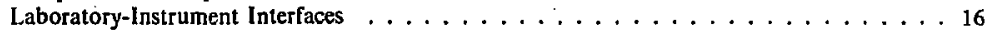

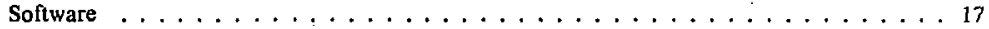

Option 2: Standard EPA System with Communication to a PDP-11 SFC . . . . . . . . . . 17

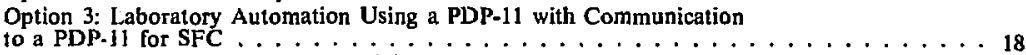

Appendix B. Details of One-Time Costs for Three Systems . . . . . . . . . . . . . . . 19

Computer and Peripherals $\ldots \ldots \ldots \ldots \ldots \ldots \ldots \ldots$

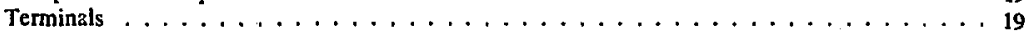

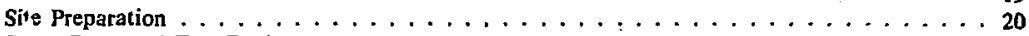

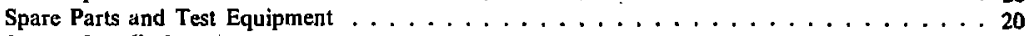

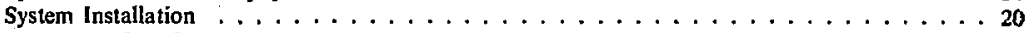

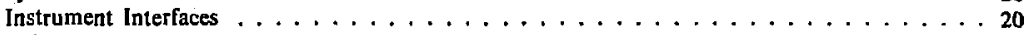

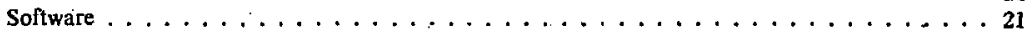

Appendix C. Detailed Assessment of Autumation Beneftis . . . . . . . . . . . . . . 22

Instrumental Methods . ....................... 22

Quality Control . . . . . . . . . . . . . . . . . . . . . . 23

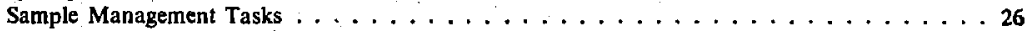

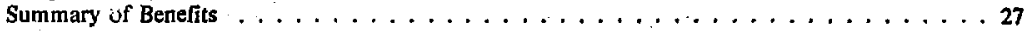

Appendix D. Breakdown of Added Operating Costs from Automation . . . . . . . . . . . 28

Appendix E. New Personnel Skills and Capabilities Recommended for the Automated Laboratory . 29 


\title{
FEASIBILITY STUDY FOR COMPUTERIZED AUTOMATION OF EPA REGION II TECHNICAL SUPPORT BRANCH
}

\begin{abstract}
Three options are presented for automating the laboratories at the Surveillance and Analysis Division, Environmental Protection Agency at Edison, New Jersey. We found each option to be cost effective. For two of the systems, existing EPA laboratory software would be used without (option 1) and with (option 2) data management: For the third system, laboratory and data functions would be implemented on a different computer (PDP-11) from those now installed: Option 2, the most favorable system, would make use of existing programs and data-management features now being developed; it would break even in $1.82 \mathrm{y}$ and accumulate $\$ 373,928$ in the five years after installation.

\section{INTRODUCTION}

In this report we describe a feasibility study for the automation of the chemistry Jaboratories of the Surveillance and Analysis Division of the Environmental Protection Agency (EPA) Region II Office in Edison, New Jersey. The objectives of this study are to establish a comprehensive definition of the current and future automation requirements of the Technical Support Branch and to present a cost/ benefit analysis of systems that will fulfill the requirements.

Specifically, we address the needs and objectives of the Region II Technical Support Branch, although these objectives also coincide with certain general objectives of the EPA. One of the current primary objectives of the EPA is to improve the retiability of data and reports generated by all EPA laboratories. To realize this, EPA is actively promoting the use of more quality-assurance checks and adopting optimized standard laboratory procedures. Because these endeavors add to the laboratory workload, automation techniques are being promoted to handle the workload and reduce

the probability of human errors.

Since 1973, the Environmental Research Center (ERC) at Cincinnati and the Lawrence Livermore Laboratory (LLL), in a joint project, ${ }^{1}$ have specified, designed, and placed in operation three laboratory automation systems. These systems are located in the Environmental Monitoring and Support Laboratory (EMSL), and the Municipal Environmental Researci Laboratory (MERL) in Cincinnati, Ohio and the Region $V$ Survejllance and Analysis laboratory in Chicago, Illinois.

These systems have been designed with the EPA primary objective in mind. At the same time, the systems have evolved into a powerful common design that meets the special needs of water analysis laboratories. This common design represents a substantial investment $(\$ 500,000)$ by EPA in terms of specifications, fundamental systems design, hardware interface design, and software. Thus, this design should receive primary consideration as a proposed system for automation of a candidate laboratory such as the Region II facility.
\end{abstract}

\section{MISSION OF REGION II}

Region II is a field operations unit of the EPA whose area of operations includes New York State, New Jersey, and Puerto Rico. The main laboratory facilities are located at Edison, New Jersey with a : small field laboratory at Rochester, New York. The primary purpose of the laboratories is to provide surveillance and analytical information, which are transmitted to the data storage and retrieval 
(STORET) function of the Water Quality Control Information System of the EPA in Washington, D.C. The Edison facility is required to respond quickly and reliably to emergencies, to aid other regional offices when necessary, and to provide assistance to states in their efforts toward environmental protection.

The mission of Region II is coordinated through three main branches under the director of the Surveillance and Analysis Division: (i) the Emergency Response and Inspection Branch, (2) the Surveillance and Monitoring Branch, and (3) the Technical Support Branch. The Technical Support Branch is responsible for the technical field and laboratory studies of the laboratory. This branch consists of the microbiology, biology, chemistry, and pesticide laboratories (at Varick Street, New York City), and the Operations and Review Section. The Region II Office receives some data management (STORET) support from the Data Systems Branch in New York City.
Region - II is primarily concerned with water pollution and is moderately involved with surveys for compliance to lead standards in gasoline. Region II also undertakes some air pollution studies and surveys.

The Laboratory's main water-study activities include ocean dumping surveys and inspections of applicants facilities for National Pollutant Discharge Elimination System (NPDES) permits. This includes the inspection of municipal, feoeral, and industrial waste treatment plants. Region II also provides surveys of t.unicipal water supplies for compliance with drinking-water standards.

On the average, the effort of Region II is divided among five studies.

- $70 \%$ NPDES water enforcement.

- $20 \%$ ocean-dumping enforcement.

- 5\% water enforcement (water supplies and other).

- $3 \%$ gasoline compliance.

- $2 \%$ miscellaneous.

\section{IHOW REGION II FULFILLS ITS MISSION}

Independent of the type of samples that Region II processes, there are certain common procedures to every investigation that require the cooperation of all branches and form a basis for describing how Region II carries out its mission.

A typical study embodies six phases: (1) planning, (2) preliminary field reconnaissance, (3) field work, (4) laboratory work, (5) evaluation and interpretation of data, and (6) reports.

Although all branches cooperate in all phases of a study, not all will contribute proportionately in each of the six phases; rather, they will contribute when or where their expertise is needed. For example, when conducting preliminary field reconnaissance, the Surveillance and Monitoring Branch contributes substantially to the planning phase. The Technical Suppist Branch also inputs to the planning phase although performing the laboratory work is its main function. Field work is a coordinated effort by Surveillance and Monitoring and Technical Support with participation by Emergency Response and Inspection. Final reports are compiled with contributions from all of the branches involved.

\section{Planning}

Before conducting an on-site investigation, survey, or study, a mandated work plan from EPA Headquarters in Washington, D.C. (a product of a resource-planning meeting) is matched with Region
II work schedules. Background information is then compiled. The division or laboratory (or both) maintains a data base upon which to plan a survey, when data are available. Water-enforcernent study runs are generally based on permit requirements, but actual concentration data are often limited. For ocean surveys, the laboratory has accumulated a sufiicient data base for useful planning analyses. Because of the difficulties in accessing analytical data from previous runs, little data are generally retrieved in the survey planning stages, a deficiency that makes analytical planning more difficult. The information is evaluated to establish whether a preliminary site reconnaissance (survey) is needed, and to design a study plan that includes an adequate sampling program within a reasonable time to carry out the freld and laboratory investigations.

A study coordinator from each involved branch coordinates the activities of that branch relative to the survey. Preparations are then made to insure the availability of resources including personnel, field and laboratory testing capabilities, and available equipment and supplies.

Before going into the field, there is a briefing session to review all aspects of the survey. For example, Technical Support will review the nature and numbers of samples. the parameters to be determined in the field and in the Edison laboratory, the holding times of samples, any unusual tests to be made, time schedules relative to sampling, their 
shipment from the field, expected arrival at Edison, chain-of-custody procedures, and reporting of results.

Importantly, the tasks may differ in scope from survey to survey, and sometimes require application of a completely new set of tests.

\section{Preliminary Reconnaissance}

A preliminary reconnaissance is usually made by the Survcillance and Monitoring team to validate background information and data to be used in the study. This of en consists of a plant walk-through to check the number, location, and flows of plant discharges for sampling purposes, any operational problems, possible locations ior mobile laboratories, and other information to aid in planning the study.

\section{Field Work}

Field work is not the same for each branch. The overall goal is to conduct a well-coordinated survey. Unique tests from the chemistry and biology laboratories, mesy of which are nuade in mobile field laboratories, support the Surveillance and Monitoring inch. Because each study or survey may be different, much effort is needed to set up and equip the laboratory and schedule the required survey lests. For example, when the Technical Support Branch field team arrives at the study site, they will set up the mobile laboratory, prepare reagents and glassware, and run preliminary standard tests to be certain that the methods and instruments are functioning properly. Region If maintains one Mobile Laboratory at Edison and one at Rochester ihat are used on-site to monitor bacteriolo ${ }_{c}$ ical changes, biological oxygen demand, $\mathrm{pH}$, total suspended solids, and other time-sensitive tests. There is also an Air Mobile Laboratory at Edison containing instruments for the analysis of $\mathrm{SO}_{2}$, $\mathrm{NO}_{2}$, oxidants, methane and nonmethane hydrocarbons, $\mathrm{CO}$, and a tape sampler for particulates in air. The data is collected on a $W$ ang 600 and reduced from the tape on a second Wang 600 for printout of hourly averages and other data on a typewriter.

\section{Laboratory Work, Data, and Reports}

Field data is entered on the Field Data Sheet, which corresponds to a laboratory number attached to the test sample. Sample numbers are matched against the descriptors and parameters in the field, on receipt at the laboratory, and by each analyst. Preliminary reports are issued to the originator of the study if, due to backlog, a parameter will not be tested until later.

Most data is forwarded on the "Form for Storage of Water Quality Data" for entry into the STORET system. Essay-type reports are prepared for oil identification or other ciualitative data. Data for gasoline lead is entered on the prenumbered "Inspection of Retail Gasoline Outlet" report. Biology reports are usually essay type. The results are stored in the Laboratory Data file with the quality-control data for an indefinite period.

\section{FUNCTION OF THE TECHNICAL SUPPORT BRANCH}

The Technical Support Branch participates in all six phases of a typical survey. The primary functions of the branch are to provide reliable data as quickly as possible in the field and laboratory.

The activities within the Technical Support Branch differ from those of the other branches. This is because much of the time must be spent on complex chemical analyses (e.g., tests using AutoAnalyzer, atomic absorption, chromatographic, and gas chromatographic-mass spectrometer methods) of water and gasoline surveillance surveys, and quality-control records.

\section{Analyses}

Many different variables are determined in the Region II Edison laboratory for the most part by instrumental techniques. Some of the more frequently used instruments are: atomic absorption, Technicon AutoAnalyzer Sy'stems; optical-emission, visible, and ultraviolet spectrometers; gas and liquid chromatographis and GC-MS instruments; and carbon analyzers. Manual multistep tests like biological-oxygen-demand analyses are also used.

Surveys differ markedly in the type and number of requested tests. In some surveys, the requests may distribute the workload over the full range of analytical methods, while other surveys may concentrate on only a few methods.

This varying worklogd distribution requires that the Technical Support Branch maintain personnel, expertise, and equipment to respond to the many different requests that are mace throughout the year; the branch must also be capable of responding to an intensive wurkload in a specific area of expertise. 


\section{Division of Responsibility}

The Survillance and Analysis Division director is responsible for the surveys, studies, case preparations, and other activities made at the Region II facility in Edison. Generally, work is scheduled on the basis of the weekly work plans submitted to the chief of the Technical Support Branch after consultation of the chief chemist and microbiologist about laboratory resources. The section chiefs assign the test to be made to members of each section through the Official San:ple Control And Repository (OSCAR). The analysts set up their schedule of work on the basis of this guide. The OSCAR coordinator must keep the laboratory supervisors and key personnel informed of any changes in the work plan, especially about the numbers and kinds of samples to be taken and the time the results are needed. Decisions must be made about recommended maximum sample holding times and the resources and time zvailable to test the samples in the field and laboratory. Throughout the course of the study, the OSCAR coordinator must insure that the identification and integrity of the samples and data are maintained and documented according to the chain-of-custody procedures.

\section{Information and Data Flow, Chain of Custody, Records, and Reports}

Samples are labelled in the field with a station identification, sample location, a laboratory number taken from a prenumbered "Field Data Sheet", date and time of sampling, and sampler's name or initials. For samples originating from other sources, the Field Data Sheet and laboratory number is completed and assigned in the laboratory.

Upon receipt at the laboratory sample receiving station (OSCAR), the sample label and samples are checked for agreement. A chronological "Incoming Samples and Inventory" log and "Sample Record" is maintained at OSCAR, A "Form for Storage of Water Quality Data" is filled out by OSCAR personnel; this form provides the station identification, sampling date and time, sample type, depth or location, lab number and parameters. Parameters are taken from the "Analysis Request" form Flled ou. and approved by the chief of the Technical Support Branch or his designate. The appropriateness of containers, preservative, and holding times is also checked by OSCAR personnel before the respective samples are distributed to the analysts. The "Form for Storage of Water Quality Data" is placed in the chemical conference room to be completed by the analysts. A "Chain of Custody Record" for enforcenient samples is completed by the originator of the "Analysis Request" form and signed by the chief chemist, who assumes responsibility for the samples while they are in the laboratory. Samples are generally consumed during the analyses or discarded after the data has been checked.

Each analyst who participates in a study refers to a copy of the work plan to schedule his work. For example, if the analyst specializes in metals analysis by atomic absorption spectroscopy, he will refer to the plan, determine the samples that fall into his analysis category, select the samples, make the analyses, calculate the results, and enter his results on the "Form for Storage of Water Quality Data."

The data are reviewed by the laboratory supervisor and then by the Technical Support Branch chief, who forwards a copy to the survey investigator. Also, a copy (with quality-assurance data) is sent to the quality-control officer, who will examine the replicate analyses and the Quality Assurance (QA) data to determine whether precision and accuracy criteria have been met. The statistical data are also examined by Shewhart control chart procedures to assure the data are within acceptable control limits. If these limits are exceeded, steps are taken to identify and correct problems in the analytical method.

The quality-control officer also checks the data for approved reporting units and for STORET compatibility. A copy of the report is ther sent to the Data Systems Branch in New York for STORET keypunching.

\section{APPROACHES TO AUTOMATION}

\section{Scope and Constraints}

Laboratory automation systems have been designed and installed in three EPA water-analysis Iaboratories: the Environmental Monitoring and Support Laboratory (EMSL), the Municipal Environmental Research Laboratory (MERL) in Cin- cinnati, and the Region V Laboratory (CRL5) in Chicago. They accommodate the operation of several of the same instrunient types that are used by Region II for water-sample analyses. The systems represent it large EPA investment in hardware and software, and it is imperative in this 
study that they receive primary consideration relative to the needs of Region II.

In the preceding sections, we have described the overall mission and functions of the Region II facility. All branches could greatly benefit from an in -house computer system. This feasibility study considers only a computer system that fulfils automation of laboratory instruments, data reduction, and other closely related operations allowing it to handle a greater lahuratory workload quickly and reliably. Nevertheliss, the above constraints do not necessarily preclude future expansion to accommodate other Region II needs at Edison.

\section{Goals of the Technical Support Branch}

The goals of the Techinical Support branch can be reduced to two fundamental ubjectives: (1) respond quickly to analysis requests, and (2) make the analyses reliably. These are continuing goals that have been met in the past by new analytical instruments and by improving existing methods and techniques. Further improvements appear to be possible through the use of computer automation in the laboratory. The objectives are to provide the means to the following.

- Link individual laboratory instruments into a system that will acquire and process data for quality-sontrol tests, and store the data for subsequent recall for compilation of a summary-analysis report.

- Determine quality-control results during the time sanules are run.

- Perform quality-control studies to establisn the data acceptability.

- Assure the integrity and retention (back up) of the aralysis data such that no data can be altered or lost.

- Track chain-of-custody of the samples as they move from one person to the next.

- Lessen the sumber of data transcriptions and make caliulutions more rapidly.

- Reduce or eliminate possible errors made in these steps.

- Enter data off-line from low-use and nonautomatec methods.

- Log in sainples, their identity, descriptions, the analysıs raquested, changes in the study plan, and other information pertinent to the analyses ard eventual report.

- Determine the status of individual or groups of samples and the parameters coinpleted rclative to the study plan.

- List work schedules of samples or variables to be tested.

Many analytical determinaticns are made in mobile laboratoris:s in the field, especially some time-sensitive determinations required for some water-sample studies. The procedures for these determinations require numerous data transcriptions, calculations, and the maintenance of record sheets. Where appropriati; the data from these tests must be included in the Region II databank to make available comprehensive computer-generated reports.

\section{Instruments for Automation}

Some of the instruments used in the Technical Support branch laboratories are the same as those already automated in other EPA laboratories. They are the best candidates for automation because most of the soliware has been developed and the hardware interfacing designed. The only cost incurred by Region II would be that of fabricating the interfaces. The instruments that fall into this category are:

- Perkin-Elmer AA spectrometer 403 (2 instruments).

- Perkin-Elmer Automatic Sampler AS-1.

- Technicon AutoAnalyzer Il (2 instruments).

- Technicon Auto Analyzer II (2 units, modified CSM-6).

- Technicon sampler IV.

- Beckman Model 915 carbon analyzer.

- Mettler electronic balance.

- Jarreil-Ash ICP emission spectrometer,*

Instruments that do not fall in:o these categories, but require some additional automation or modification to already existing automation development are:

- Perkin-Elmer Model 460 with HGA 2100 furnace.

- Finnigan chemical iouization GC/MS system.

- Finnigan electron jonization GC/MS systein.

- Oceanographic International total carbon analysis system.

- Perkin-Elmer Model 202 UV/visible spectrophotometer.

\footnotetext{
*The Jarrell-Ash ICP emission spcctrometes contains its own computer for data acquisition, reduction, an's individual-sample report generation with data outpu! by means of punched paper tape.

The use of the ICP emission spectrometer by Region II is not included in this analysis; however, experience at other laboratories indicutes that additional duta handling capacity is required to store data and manipulate results for multiple samples. Work is underway to develop efincient means of transferring data to the laboratory uutomation system to facilitate the sdditional data-reduction capability. The dollar value of this bentefit and the costs to implement it cannut now be determined.
} 
These instruments, the measurements taken, and the maximum workloads per survey are briefly described in the following sections.

\section{Atomic Absorption Spectrometer}

The atomic absorption spectrometer is used to determine the levels of metals in water samples. The instrument contains a characteristic atomic-line source (hollow cathode lamp) of the metal to be determined, a flame or furnace source for exci ag metals in the sample, a monochromator to select light of the appropriate wavelength, and a photomultiplier whe to detect the light. Water samples are aspirated into the flame or injected into the furnace, which is positioned between the hollow cathode lamp and the monochromator-detector. Neutral atoms of the metal of interest absorb the characteristic light from the hollow cathode, and the instrument detects and measures decrease in iight energy (absorption). The value can be read on a digital display in absorbance units or directly in concentration, which is proportional to absorbance.

Two Perkin-Elmer spectrometers (models 460 and 403) have been used to determine approximately twenty different metal elements in v/ater samples. Model $1^{2} 6$ has an AS-1 automatic sampler as an integral part of its system.

\section{Teclinicon AutoAnalyzer}

The AutoAnalyzer performs continuous-flow, multiple-chemical analyses. The system aspirates samples in sequence, brings sample and reagent together for reaction to form a colored solution, and continuously moves the sequence of samples through predetermined analysis steps. The analyzer moves the colored solution through a colorimeter where its light absorption is measured. The concentration, which is proportional to absorbance, can be presented ou a recorder or digital tape. A sixchannel Technicon CSM-6 analyzer (modifted as two TAA IIs) and two Tecl:nicon AutoAnalyzer IIs are used for the determination of analytes such as phenol, Kjeldahl nitrogen, $\mathrm{NH}_{3}, \mathrm{NO}_{3}-\mathrm{NO}_{2}$, and various forms of phosphorus. The amaiyzers have automatic samplers as integral parts of the system.

\section{Mettier Electronic Balance}

The Mettler balance to be used will be the recent Model HLS2 electronic analytical balance. The balance is used most often for weighing total suspended solids in water and for organic and bottom-sediment analyses. The number of weighings on the electronic balance will be high: about 1,000 suspended solids analyses requiring two weighings each, and 500 to 600 organic and bottom sediment analyses requiring six weighings each will result in approximately 5,000 to 5,600 weighings ar:nually.

\section{ICP Optical Emission Spectromister}

Multielement determinations of trace metals in water samples and residues are made using a JarrellAsh optical spectrometer equipped with an inductively coupled, argon-plasma excitation source. The sample is nebulized to an aerosol in hightemperature argon that is heated as the gas passes through a radio-frequency field. Radiation from the plasma that is characteristic of the excited argon and inipurity atoms is dispersed in the grating spectrometer and focused on separate slit-photomultiplier tubc assemblies (channels) precisely arranged along the focal plane of the spectrometer to detect each element of interest. The signals for individual samples deterted in each channel are processed by a minicomputer and typed out directly in. concentration units for each element. The minicomputer is an integral part of the spectrometer.

The optical emission spectrometer is currently being used for the determination of metals on unregulated samples. It has high precision and accuracy, equivalent to atomic absorption for many elements, but can process more sariples in time.

\section{Total Organic Carbon Aanlyzers}

Total organic carbon is determined by combustion of organic matter to convert the carbon to carbon dioxide which is detected as it passes through an infrared analyzer. The two instruments that are used for this determination are the Beckman Modei 915 Carbon Analyzer and the Oceanographic International Total Carion System.

With the Model 915, a measured volume of the test solution is injected into a combustion furnace where a continuously flowing stream of oxygen converts the water to water vapor and organic carbon to carbon dioxide. The water vapor is condensed and trapped as the gases are carried out of the furnace, and the carbon dioxide is carried through the infrared detector and teleased to tije exhaust. The infrared detector generates an electrical signal that is converted to a voltage proportional to the amount of carbon dioxide passing through the detector. The voltage is recorded on a strip-chart recorder, and the amount of organic carbon present in the injected solution is calculated by comparing the recorded voltage with that for a standard solution containing a known amount of organis carbon.

The Oceanographic International carbon analyzer consists of a sample preparation and analyzer unit. $U p$ to $10 \mathrm{ml}$ of sample are placed in a borosilicate ampule, and potassium persulfate is added. To remove pre-existing carbonate, the mixture 
is acidified and purged with oxygen. The ampule is then sealed, and the organic matter oxidized to $\mathrm{CO}_{2}$. The ampule is then transferred to the analyzer unit where the seal is broken, and the quantity of carbon as $\mathrm{CO}_{2}$ is measured with a nondispersive infrared anglyzer.

\section{Ultraviolet and Visible Spectrophotometer}

A Perkin-Elmer Model 202 UV/visible spectrophotometer is used. The spectrophotometer consists of interchangeable, tungsten-filament (visible) and hydrogen (ultraviolet) source lamps, samplesolution cells, a monochromator, and a detector. The solution cell containing the sample is placed in the light path between the suurce lamp and the monochromator-detector. Light passing through the solution is absorbed by the analyte over a wavelength band characteristic of the analyte. Measurements are made in absorbance units; absorbance is proportional to concentration. Phenol, cyanide, and MBAS are the most frequent spectrophotometric determinations made.

Automation of the Perkin-Elmer 202 is not is. cluded in this study because it is used so infrequently at the Edison facility.

\section{Other Instruments}

The chromatographic and Finnigan GC-MS instruments are integrally automated or semiaut omated, and therefore further automation linked to a laboratory automation system is 1 . Ct now justified. Additional software and hardware to link the data output of these instruments to the central data system is possible, but not included it this study.

Other instruments are used in the laboratory such as sullur analyzers, zutomatic titrators, ozone analyzers, nitrogen oxide analyzers, $\mathrm{pH}$ meters, and a polarographic analyzer. The workloads on these instruments are not sufficiently high to warrant the development of hardware and snftware for their automation. If desired, analytical results from them can be manually entered into the conputer data base, which would require some additional software.

\section{Instruments Selected for Automation}

For this feasibility study the following instruments (inumber available) have been selected for automation at the Region II Edison facility:

- AutoAnalyzer II unit with Technicon Sampler IV (4).

- Perkin Elmer Model 460 AA spectrophotometer with HGA 2100 furnace and PE AS-1 sampler (I).
- Perkin Elmer Model 403 AA spectrophotometer (2).

- Be :kmarı Model 915 carbon analyzer (1).

- Oceanographic International total carbon system (1).

- Mettler electronic balance, Model HL52 (I).

\section{Study Plan, Job Scheduling, Coordination, and Automation of Sample Management Activities}

For each study, a work plan is devised as described previously. This plan includes sampling schedules along with the parameters to be determined and will establish a data base into which will be placed the data from chemical tests made in the field and at the Edison latoratory. The study plan provides the sched ules by which the Technical Support branch can plan its work, determine the status of a survey, fulfill changes therein, and generate reports.

Throughout the cuurse of the survey, there are many transcriptions of information and data in the tield and the laboratory (Fig. 1). Records of infermation and data maintained by all of the laboratory participants are numerous, and must be compiled into a unified report. The present system requires much coordination and diligent rechecking to ensure that the information and data flow are correct and proceed smoothly within the time constraints set by the study plan. Establishing a sample data file could be made more efficient and reliable if data acquisition, information and data transcriptions, and record xeeping were minimized. This would apply throughout the survey from sampling log-in, analysis, data logging, calculations, data compilation, and generation of reports.

In this study, Sample File Control (SFC) is delined as an automated system to create and allow interaction with a sample data fite. Such a system would facilitate the determination of the momentary status of any given sample or group of samples. The following is a list of minimal SFC functions that are candidates for atutomation.

\section{Water Quality Data File}

A water quality data file is created that will be available in one or more computer files to be accessed for local laboratory work schedules and to determine the status of the work plan relative to parameters in samples completed. The file also provides hard copy.

\section{Water Quality Data File Update}

Provisions are made for updating the computer files with analysis-results and changes in the work plan. 


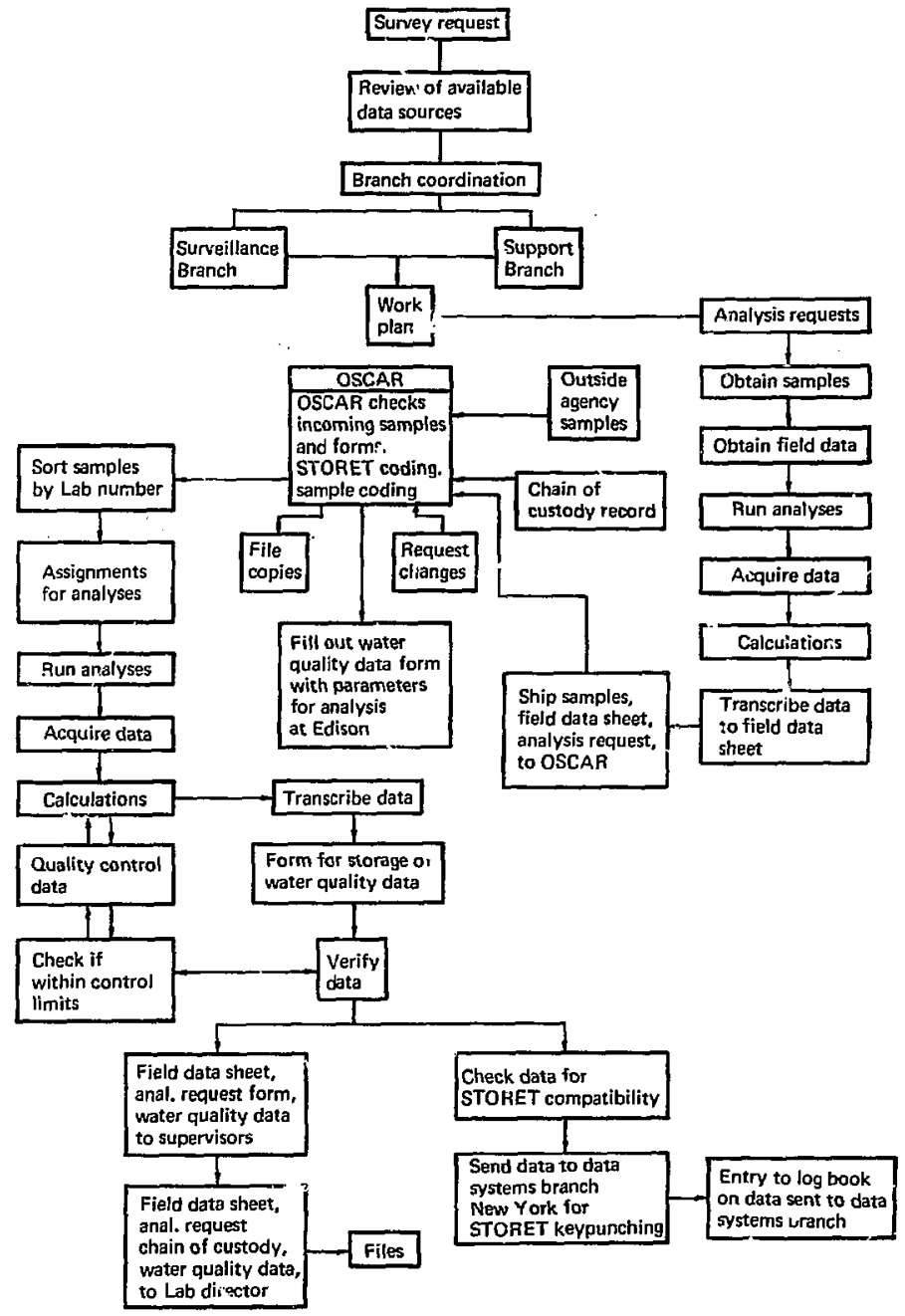

Fig. 1. Survey information and data fos. 


\section{Sample Reruns}

The means are provided to amend the water quality data file 'with approved results from samples that have been rerun.

\section{Completed Samples}

The means to review all analysis results of completed samples are provided for the purpose of ap. proving the final analysis report as being ready for STORET. Hard copy is also provided alung with the means to transmit these data to STORET.

Sampies in Process

A means to list all samples having incomplete data with hard copy is provided.

\section{Laboratory Work Scisodule and Analysis File}

A loral analysis fi'e is made available by listing samples to be run according to a common. parameter test. Hard copy is a'so provided.

\section{Laboratory Analysis File Update}

Provisions are made for updating the locai analysis file with results as they are generated.

\section{Analyst's Report}

The means to list an analys:'s completed analyses and quality controls is provided with hard copy. The hard cofy can be di ad and signed by the analyst and QC officer and retained as litigation backup evidence.

\section{Chain-of-Custody}

A file for recording sample chain-of-custody with hard ropy is provided.

\section{Entry of Field Analyses}

A means is provided for entering field data into the water quality data computer file.

\section{PROPOSED SYSTEMS FOK FULFILILING THE REQUIREMENTS OF THE. TECHNICAL SUPPORT BRANCH LABORATORY}

We propose thrce optional automaticn systems, briefly described below. More details about these three options are presented in Appendix A; the configurations are shown in Fig. 2; the one-time system costs are listed in Table 1 and $A$ ppendix $B$. In this table, the costs pertain to the computer and peripherals, the hardware interfaces, the software, site preparation, spare parts, test equipment, and system installation. Also included for options 2 and
3 are the costs for communications hardware and software that allow the laboratory automation system to communicate with a remote (regional) management system for the SFC functions listed in the previous section. The management computer system (DEC PDP 11/70, proposed) presumably will have been justified separately for regional management needs and will not be a cost incurred by Region II Technical Support Branch.

Table l. Summary of costs for the proposed optional computer automation systems.

\begin{tabular}{|c|c|c|c|}
\hline Iten. & $\begin{array}{c}\text { Option 1: } \\
\text { data zeneral } \\
\text { lab., avcomation } \\
\text { only }\end{array}$ & $\begin{array}{c}\text { Oplion 2: } \\
\text { data general } \\
\text { laö., autor.ration } \\
+ \text { communication } \\
\text { with SFC }\end{array}$ & $\begin{array}{c}\text { Option 3: } \\
\text { digital tquipment } \\
\text { lab., automation } \\
+ \text { comınurication } \\
\text { with SFC }\end{array}$ \\
\hline Computer and peripherals & $\$ 82,866$ & $\$ 119,406$ & $\$ 180,674$ \\
\hline Terminals & 22,000 & 31,800 & 31, , 0 \\
\hline Site preparation & 15,000 & 15,000 & 15,000 \\
\hline Spare parts and test equipment & 10,300 & 10,000 & 10,000 \\
\hline System installation & 40,000 & 40,000 & 40,000 \\
\hline Instrument interfaces & 34,300 & 34,300 & 40,041 \\
\hline Software & No cost & 20,000 & 181,500 \\
\hline Total one-tíme c sts & $\$ 204,166$ & $\$ 270,506$ & $\$ 499,015$ \\
\hline
\end{tabular}

a Assuming no modifications required to existing software now being used with the standard EPA Automation package. 


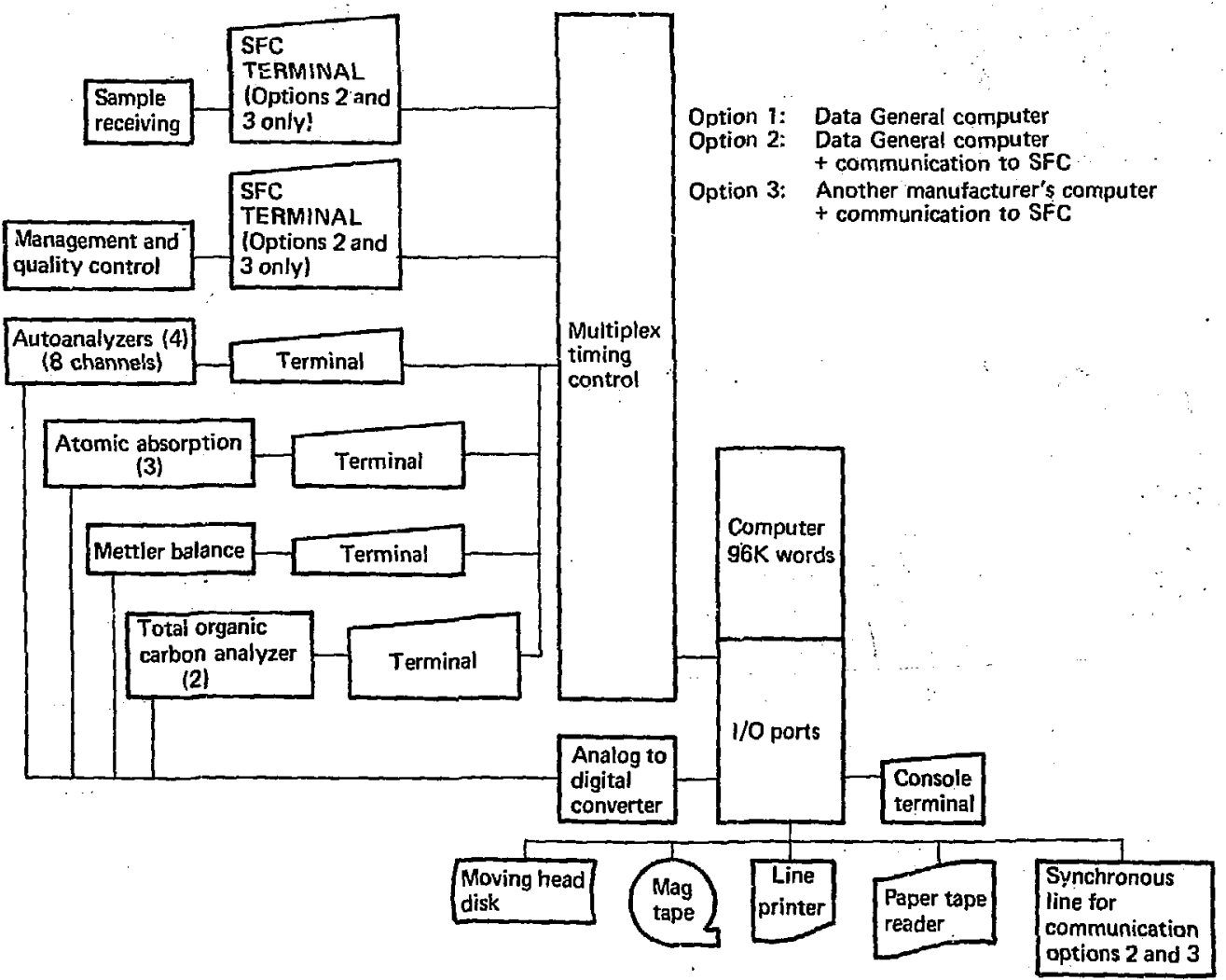

Fig. 2. Three proposed options ror automation of EPA Reglon II laboratory. 


\section{Option 1}

The first option is based on the EPA standard laboratory automation design currently installed in water-analysis laboratories in Cincinnati and Chicago. The system incorporates a Data General computer with the MRDOS operating system and Basic language programming capability. The ECLIPSE S/230 was chosen for costing purposes. The choice of the computer should be deferred until the implementation design phase because other computers may become available for the agencywide system. The EPA system also includes laboratory instrument interface designs and BASIC language programs with assembly language routines for operation of the automated laboratory instruments. Descriptions of the computer hardware, the interfaces, and software comprising the system are given in Appendix A. Although the proposed system embodies the current EPA design, the computer hardware dif:ers from the currently installed systems in that more recent designs of the central processor and peripheral devices are proposed. The new generation equipment remains largely compatible with the analytical instrument hardware interfaces and applications programs developed for the standard system.

\section{Option 2}

The second option is an outgrowth of the EPA decision to adopt the PDP-11 system (Digital Equipment Corporation) for decentralized processing by regional offices. This option includes the standard EPA laboratory automation system (same as option 1) with added hardware and software to communicate with a host PDP-11 (in the regional office) for SFC functions.

\section{Option 3}

Option 3 also considers the EP 1 comnitment to PDP-Il computer systems lo automate the laboraiory. This option would include hardware and software to communicate with an additional PDP-11 for SFC functions.

\section{COST-BENEFIT ANALYSIS}

\section{Introduction}

Three optional systems have been proposed to fulfill the needs of the Region II laboratory. We must now show the extent to which Region II can justifiably incur the costs against the benefits it can expest to derive from these proposed systems. It is the purpose of this analysis to place a dollar value on the benefits vs the dollar costs.

\section{Basis for the Analysis}

To analyze this problem, we used the workload derived from Region II data for 1976 and the projected estimate for 1977 based on the actual workload thresth May 1977. We compared the effort and operating costs required to meet the load with and without automation.

The data shown in Table 2 are based on the determinations made at the Edison facility and do not include field determinations. The numbers given for the total determinations per year a e exclusive of determinations made for quality control.

The effort of the Technical Support branch personnel can be broken down into three categorjes: (1) adninistrative and supervisory tasks, coordination and collation of studies, and summarizing of analysis data; (2) laboratory work; and (3) quality control. The present expenditures are shown in Table 3 in amounts of full-time employees (FTE) required (i e., 0.5.FTE is half of a full-time employee's time).

Quality-control standards are run to check all analytical methods. The time devoted to their preparation and running is not included in the effort of the quality-control officer, but in the laboratory personnel's effort. The tasks of the quality-control officer are to make certain that quality-control procedures are followed and criteria are met.

Our intent in this study is to estimate the benefits that will accrue to the Technical Support branch in the best areas for automation. Briefly, these include on-line automation of the Technicon AutoAnalyzers, atomic absorption spectrometers, tlectronic-balance operations, and total organiccarbon analyzers. The other prime area for automation includes study-coordination and sample-filecontrol functions such as $\log$-in and work scheduling.

\section{Comparison of Costs and Benefits}

To assess the cost benefits to Region Il as a result of automation, we compared the effort that will be expended in the instrumental analyses, sample coordination, and management areas by manual methods to the expected effort by computerautomated methods.

The increased efficiency after automation can be expressed as full time employee (FTE) effort made 
Table 2. Analysis methods and percent of determinations performed.a

\begin{tabular}{|c|c|c|c|c|}
\hline Method & $\begin{array}{c}\text { Number of } \\
\text { camples/y }\end{array}$ & $\begin{array}{c}\text { Number of } \\
\text { parameters/ } \\
\text { sample }\end{array}$ & $\begin{array}{c}\text { Total } \\
\text { determinations/y }\end{array}$ & $\begin{array}{l}\text { Determinations } \\
\text { of to } a l, \%\end{array}$ \\
\hline Atomic absorption & $\begin{array}{c}570 \\
\left(H_{2} O \text { \& sedlment) }\right.\end{array}$ & 7 & 4,000 & 17 \\
\hline Atomic absorption & $\begin{array}{c}3, c 00 \\
\text { (gasoline) }\end{array}$ & 1 & 3,000 & 12 \\
\hline AutoAmalyzer & $\begin{array}{c}860 \\
\text { (nutrients) }\end{array}$ & 7 & 6,000 & 25 \\
\hline Emission spec & $\begin{array}{c}225 \\
\text { (metals) }\end{array}$ & 18 & 4,000 & 25 \\
\hline Total organic carbon & 2,000 & 1 & 2,000 & 9 \\
\hline GC/MS & 600 & 5 & 2,500 & 11 \\
\hline Gravimetry & 1,000 & 2 & $2,000^{b}$ & 9 \\
\hline
\end{tabular}

${ }^{B}$ Based on average 1976 and projected 1977 data.

bepresents approximately 6,000 wcighings-

available for other tasks such as making more analyses or surveys. Benefits, expressed as increased efficiency, are summarized in Table 4. Details of this assessment are give $n$ in Appendix C. On-jine instrument automation and quality control $(Q C)$ will

Table 3. Full-time employee (FTE) expenditures for the Technical Support Branch.

Administrative tashs

\begin{tabular}{ll}
\hline Branch supervisor & 0.1 \\
Chemistry supervisor & 0.5 \\
Biology supervisor & 0.2 \\
Secretary & 0.5 \\
Login slation (OSCAR) & 0.8 \\
Chemist administrative duries & $\underline{0.5}$ \\
\multicolumn{1}{c}{ Total } & 2.6
\end{tabular}

Laboratory tasks

Metal analyaes

Orgaric analyses

TOC and inorgantc analyses

Miscellaneous analyses

Total

$\overline{9.7}$

Quality-control tasks (supervisory)

Quality-control officer

Other operatlons \& review

1.0

Total make available $3.36 \mathrm{FTE}$, while san ple management automation will free another 2 FT. B. Because the laboratory's expected average annual cash output per employee is ar proximately $\$ 45,600, *$ the savings attributable to laboratory automation and QC is equivalent to $\$ 153,200 / y$. The savings in management effort is equivalent to $\$ 91,200 / y$. Thus, the total savings accrued to Region II is $\$ 244,400$ annually.

The one-time costs for each of the three proposed optional automation systems are listed in Table $\mathbf{I}$. In addition to these costs, it is essential to include

\footnotetext{
This assumes a median salary level of $\$ 21,000 / y$ multiplied by 1.3 and 1.67 to account for benelits and overhead. respectively.
}

Table 4. Sunmary of benefits.

\begin{tabular}{lc}
\hline Candidate area for automation & $\begin{array}{c}\text { Effort efficiency from } \\
\text { automation, FTE }\end{array}$ \\
\hline Instruments & 2.41 \\
Quality control & $\frac{0.95}{3.36}$ \\
Subtotal & $\underline{3.00}$ \\
Sample management & $\overline{5.36}$ \\
\hline
\end{tabular}


the annual maintenance and operating costs of the proposed systems. These costs, which are above any current annual costs, are $\$ 30,000$ for option 1 , $\$ 58,400$ for option 2 , and $\$ 65,700$ for option 3. Option 2 and 3 costs are higher than option 1 costs because of the maintenance and operation of communications with SFC. A description and breakdown of these costs for the three options are given in Appendix $D$.

\section{Costs and Benefits Relative to Payout Time and System Life}

To determine whether it is feasible to automate the Region Il Laboratory, the benefits derived from automation must be weighed against the costs of the auiomation system. In this analyses, we use the accumulated benefits at five years' of system service and the payout time of the system as two criteria for measuring feasibility. We calculated these criteria for each of the three options. However, option 1 includes a laboratory automation system only, and does not provide communications with a laboratory management (SFC) computer. Therefore, only the savings derived from on-line instrument automation and quality control (3.36 FTE, equivalent to $\$ 153,200 / y$ ) can be considered for the first option.

Also, the annual savings for the three options must be balanced against the added operating costs incurred as a consequence of each automation option.

The first feasibility criterion, the accumulated balance at five years service, ${ }^{2}$ is calculated using the formula ${ }^{3}$ :

$$
B=b / i\left[1-l /(1+i)^{n}\right]-C,
$$

where,

$$
\begin{aligned}
& B=\text { balance after } n \text { years, } \\
& b=\text { net benefit per year, }
\end{aligned}
$$

$\mathrm{i}=$ interest rate, $10 \%$ per year $=0.1$.

$\mathrm{n}=$ number of years $=5$

and

$C=$ one-time investment cost of the system.

The second feasibility criterion, the payout time, is that time when the one-time costs will have been balanced by accumulated benefits. Thus, $B$ in Eq. (1) may be set to zero and the payout time $n$ can be solved by:

$$
\mathrm{n}=-\log (1-\mathrm{iC} / \mathrm{b}) / \log (1+\mathrm{i}) \text {. }
$$

\section{Summary of the Cost-Benefit Study}

From a cost/benefit point of view, all options of the proposed automation are economically justifiable. Net equivalents in increased-effort efficiency of $\$ 262,859$ (option i), $\$ 373,928$ (option 2), and \$117,746 (option 3), will be accrued by Region II over an expected 5-y system-service life. Also, the original investınent costs will have been paid up in 1.90 y (option 1), 1.82 y (option 2), and 3.84 y (option 3).

There are other benefits of automation that will accrue to Region II that will directly influence its mission to respond quickly to emergencies. On-line automation in the laboratory and a link with a sam. ple management system will allow the laboratory to complete a study or survey at least twice as fast. Thus, the laboratory can respond more favorably to peak-load work.

Rapid quality assurance can also be realizei with the proposed automation systems. Presently, Region II sample workload includes approximately $50-80 \%$ quality controls such as repeat standards and duplicate and spiked unknowns.

The costs and benefits and the calculated

\begin{tabular}{|c|c|c|c|}
\hline Item & $\begin{array}{l}\text { Option 1: } \\
\text { data general } \\
\text { lab., automation } \\
\text { only }\end{array}$ & $\begin{array}{c}\text { Option 2: } \\
\text { date general } \\
\text { lab., automation } \\
+ \text { communication } \\
\text { with SFC }\end{array}$ & $\begin{array}{l}\text { Option 3: } \\
\text { digital equipment } \\
\text { lab., automation } \\
+ \text { communication } \\
\text { with SFC }\end{array}$ \\
\hline One-time system costs & $\$ 204,166$ & $\mathbf{\$ 2 7 0 , 5 0 6}$ & $\$ 499,015$ \\
\hline Gross annual savings & 153,200 & 244,400 & 244,400 \\
\hline Added annual operating costs & 30,000 & 74,400 & 81,700 \\
\hline Net annual benefit & 123,200 & 170,000 & $t 62,700$ \\
\hline Accumulated balance at $5 y$ & $\$ 262,859$ & $\$ 373,928$ & $\$ 117,746$ \\
\hline Poyout time, $y$ & 1.90 & 1.82 & 3.84 \\
\hline
\end{tabular}
feasibility criteria for the three optional automation systems is summarized in Table 5.

Table 5. Summary of costs, benefits, and calculated feasibility criteria. 


\section{REFERENCES}

1. Development of Laboratory Computer Automation Systems, EPA-IAG-D6-0321, Interagency Agreement between Energy Research and Deveolopment Administration and Environmental Protextion Agency, Washington, D.C. (1976).

2. United States Government, Bureau of Budget Circular A54, Washington, D.C. (1977).

3. F. J. Stermole, Fconomic Evaluation and Investment Decision Meshods (Investment Evaluations Corporation, Golden, CO 1974). 


\section{APPENDIX A. DESCRIPTION OF THE PROPOSED OPTIONAL AUTOMATION SYSTEMS}

Three optional systems for automation of the Region 11 laboratory are described in this Appendix. The selection of the exact equipment to be used should be deferred until the implementation design phase. Other computers and peripherals that become available may be nore cost effective than the ones we have chosen for these options.

\section{Option 1: Standard EPA Laboratory Automation System- Data General Computer}

The standard EPA laboratory automation system proposed as option 1 incorporates a general-purpose Data-General computer and peripherals, laboratory instrument interfaces, and software designcd and developed for the Data General NOVA 840 computer with the MRDOS operating system. Althougb developed for the NOVA 840 , the interfaces and softwart are largely compatible with any Data-General system that also uses MRDOS.

In this section, we describe the standand EPA laboratory automation system currently in use. Included are details of the computer and peripherals and available hardware interfaces and software currently recommended.

\section{Computer and Peripherals}

\section{Computer}

The computer used in this cost analysis is the Data-General ECLIPSE S/230, general-purpose computer. Other computers possible for this purpose are the S/130, the NOVA 3/D, and the NOVA 840 . All will handle a range of software including Basic, Fortran IV, Fortran V, and Algol. These systems also have the capability to communicate with other computers by means of HASP and 2780 emulators. All qualify as general-purpose computers that are largely compatible with the standard EPA software and interface hardware while providing the capability for future growth. If another computer is chosen, it must satisfy these same requirements. In the proposed system for option $1,96 \mathrm{~K}$ words of core memory are recommended for laboratuiy instrument autom?tion.

\section{Disk Storage}

The proposed version of the standard EPA system incorporates the Data General nrodel 6060 movinghead disk, as on the Region-III system now being assembled. This proposed disk has several features that make it better than disk configurations uzed in previously installed EPA systems. The model 6060 has storage capacity of 96 Mbytes, transfers data at three times the rate and is expected to be more reliable than sarlier configurations. Although the storage capacity of the disk is far more than required to implement laboratory automation, a large capacity is recommended because smaller-capacity units do not have sufficient speed, and. combined fixed-head and moving-head units are nearly equivalent in cost.

\section{Magnetic Tape}

The magnetic tape system is used for permanent storage of software programs and as a backup storage medium (i.e., backup relative to core memory and disk) for the storage of data and information that are being accumulated over excended periods of time. The proposed version of the standard EPA system includes a nagnetic tape unit that drives the tape at $75 \mathrm{in}$./s. Experience with the currently installed EPA systems having slower tape drives indicates that a faster drive would be better, especially if data backup operations are to take place daily or more frequently.

\section{Line Printer}

The line printer in the current EPA systems is used to produce, for example, hard copy listings of programs, preliminary and final sumnary data reports, and multi-position sampler patterns. In a multi-user automation system, a fast unit is desirable; a $300 \mathrm{line} / \mathrm{min}$ unit is proposed for the Region-II system.

\section{Paper-Tape Reader}

A paper tape reader is a recommended component of the standard EPA system. It is used for system start-up and for the diagnosis of hardware problems when disk or magnetic tape are not available. 


\section{Analog/Digital Converter}

A multi-channel analog to digital converter wih full scale resolution capability of one part in 16,384 is proposed. The converter is essential for digitizing the various analog signals from laboratory instruments interfaced to the computer system. The number of channels required is equivalent to the number of analog signals that have to be processed. For Region II, a total of $\mathrm{I} 4$ channels is anticipated initially; therefore, a 16channel converter is recommended (minimum 8-channel modules are provided). This provides two channels for spares and future expansion, which should be adequate. EPA will probably limit its future purchases to instruments that incorporate a data-processing capability and are designed to be interfaced directly to computers. They contain their own analog-to-digital conversion and will not use the system's converter.

\section{Terminals}

Keyboard terminals, through which information is entered and received, are used at the computer, at the interfaced laboratory instruments, and at other potential locations such as sample-receiving and management offices. The proposed system does not include a specific terminal type because the impiementation design of the system has not been made. However, two general terminal types are used in the standard EPA system: hard copy teletype devices such as the Texas Instruments Silent 700 and the cathode ray tube (CRT) display devices. The latter may include the "roll-back" feature, allowing for rolling back lines of information or data that have disappeared from the limited-line display screen. Special terminal; equipped with a keyboard, CRT display, hard copy unit, and telecommunicatiots accessories are recommended for those options that include communication with a SFC.

\section{Laboratory-Instrument Interfaces}

The laboratory-instrument interfaces are the electronic devices that link the analytical instruments to the computer. In the standard EPA system, the instrument signal output terminal is the principa? location where interfacing has been installed. The candidate instruments for automation in the Region II luboratory can use the existing interface designs. Table A-1 lisis the currently available interface designs and their applications.

Table A-1. Currently available interface designs.

Interface

Application

General computer interiace

Technicon AutoAnalyzer I

Technicon AutoAnalyzer II

Perkin-Elmer AA spectrophotometer

Varlan Techtron AA spectrophotometer

Instrumentation Lab AA spectrophotometer

Sample wheel for AA spectrophotometer

Total organic-carbon analyzer

Jarrell ash emission spectrometer (sequential readout)

Ultraviolet-visible spectrophotometer

Graphite fumses for atomic absorption

Mettler electronic balance
Timing and control signals

Data sign日 acquisition

Data signal acquisition

Data signal acquisition

Data signal acquisition

Data signal acquisition

Random and sequential sampler control

Data signal aequisition

Date signal acquisition and monitor thannel position

Data signal acquisition

Detection of fumace cycles for control of signal acquisition

Data signal acquisition 


\section{Software}

While developing automation systems for EPA water-quality laboratories, extensive software has been developed for use in a variety of laboratory instrument applications. The software includes assemhly language coding and high-level Basic language programming. Table A-2 summarizes the programs developed to date that are considered part of the EPA standard system.

Table A-2. Standard EPA laboratory automation system - summary of applications prograns for laboratory instruments.

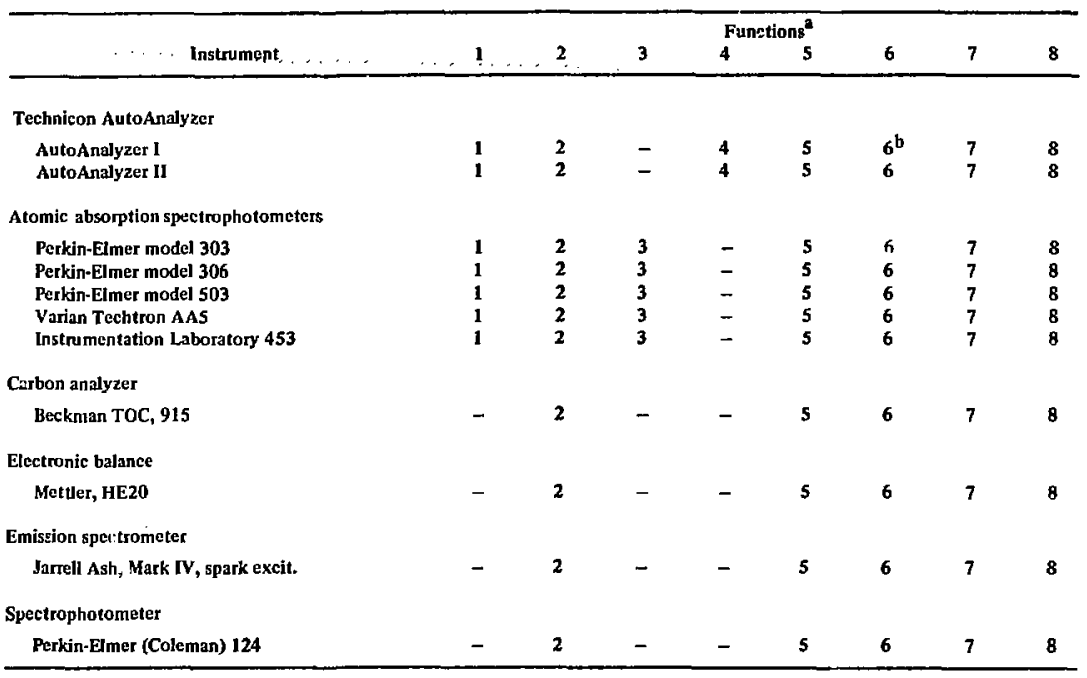

'The following is a list of functions and data reduction processes provided by the softwure:

1. Interactive input routine for setting up a schedule of samples, standards, and controls to be run on a sample changer.

2. Method and instrument operation prompts.

3. Sample-changer control and monitor.

4. Sample-changer monitor only.

5. Data ecquisition.

6. Data reduction, standards, quality-control samples.

7. On-line resuits displayed or typed.

8. Report generation (report is exclusive for each instrument).

Data reduction processes are:

- Creation of standard curves using lirst, second and third degree polynomial rits.

- Calcujation of unknown concentrations by interpolation between the two nearest standards.

- Calculations of spilke recoveries, check standards compliances, and differences between duplicates.

- Calculation of statistical error bands using Shewhart and Cussum Methods.

\section{Option 2: Standard EPA Laboratory Automation System-Data General Computer With Communications to a PDP-11 Computer for SFC}

Option 2 is an outgrowth of the EPA decision to adopt the Digital Equipment Corporation PDP-11 system for decentralized processing. It is composed of the standard EPA laboratory automation system with the Data General computer as described in option 1, including hardware and software to communicate with the PDP-11 computer for SFC functions. 
Hardware is required on both ends of the communication link. At the laboratory, a synchronous. line adaptor will be needed, while at the SFC computer, an additional disk drive and interfase will be required. Two consulc terminals equipped with a keyboard, cathode ray tube display, and printer will be needed at the laboratory end to facilitate conmunications with the PCP-11.

The ECLIPSE S/230 computer used for cost estimation contains the Data-General version of the HASP (Houston Automatic Spooling Process) tmulator for communications to the PDP-11. Appropriate software using HASP is being developed to send data to the PDP-1I through the synchronous line adaptor.

\section{Option 3: Laboratory Automation Using a PDP-11 With Communications to a PDP-11 for SFC}

As for option 2, option 3 is based on the EPA commitment to PDP-11 computer systems. The option proposes that the standard EPA laboratory system be modified in hardware and software to run on a PDP-11 system. The option includes communications to the PDP-11 for SFC functions. The modifications required include redesign of the general computer interface to the instrument automation system and extensive rewriting and debugging of the automation software. More details are presented in Appendix B. 


\section{APPEINDIX B. DETAILED BREAKDOWN OF THE ONE-TIME COSTS FOR THE THREE SYSTEMS}

\section{Computer and Peripherals}

The costs for the computer and peripherals for the three proposed optional automation systems are listed in Table B-1.

\section{Terminals}

For option 1, eleven terminals are recommended; one terminal at the computer console (that can be switched between foreground and background), one at each of six instrument installations, and four terminais for eight channels of AutoAnalyzer II instrumentation. The estimated cost of terminals for option 1 is $\$ 2,000$ per terminal, a total cost of $\$ 22,000$.

For options 2 and 3 , thirteen terminals are recommerded; in addition to the eleven described for option 1 , these include two special terminals, one each for OSCAR and QC-administrative purposes for communications with the SFC computer. Both SFC terminals will be equjpped with a keyboard, CRT display, hardcopy unit, and telecommunications accessories. The estimated cost of terminals for options 2 and 3 is $\$ 22,000$ for one console and ten instrument terminals, and $\$ 4,900$ each for the two SFC terminals. Therefore, the total cost of terminals for options 2 and 3 is approximately $\$ 31,800$.

Table B-1. Costs of computer hardware and peripheruls.

\begin{tabular}{|c|c|c|c|}
\hline Item & $\begin{array}{l}\text { Option I: } \\
\text { data general }\end{array}$ & $\begin{array}{c}\text { 0Ftion 2: } \\
\text { deta general } \\
+ \text { +link to SFC }\end{array}$ & $\begin{array}{c}\text { Option 3: } \\
\text { (PDP-11/70) } \\
\text { + link to SFC }\end{array}$ \\
\hline $\begin{array}{l}\text { Computer with 96K words core memory, floating point } \\
\text { processor, memory map, and real-time clock }\end{array}$ & $\$ 27,635$ & $527,6 \div$ & $\$ 51,660$ \\
\hline Moving-head disk, 96 Mbytes & 29,000 & 29,000 & $36,750(88 \mathrm{MB}$ \\
\hline Magnetic tapc & 14,110 & 14,110 & 26,500 \\
\hline Line printer & 11,390 & 11,390 & 11,800 \\
\hline Paper tape rcader & 1,700 & 1,700 & 5,060 \\
\hline System cabinet & 2,990 & 2,990 & - \\
\hline Analog/Digital converter, 16 channels & 6,145 & 5,145 & 6,145 \\
\hline Multiploxer asynchronous line & 3,600 & 3,600 & 3,600 \\
\hline Computer system software & 1,000 & 1,000 & 3,660 \\
\hline $\begin{array}{l}\text { Communications hardware synchronous line } \\
\text { addaptor (laboratory end) }\end{array}$ & - & 1,100 & 1,300 \\
\hline $\begin{array}{l}\text { Communications hardware full/half duplex } \\
\text { synchronous intetace (PDP-1I end) }\end{array}$ & - & 3,100 & 3,100 \\
\hline Additional disk drive, 88 Mby te (PDP-11 end) & - & 32,340 & 32,340 \\
\hline Total costs & 597,570 & $\$ 134,110$ & $\$ 181,915$ \\
\hline
\end{tabular}




\section{Site Preparation}

Site-preparation costs are estimated to be approximately $\$ 15,000 *$ They will be incurred in preparing the existing chemical conference room of approximately $330 \mathrm{ft}^{-1}$ where the coniputer can be located. The room must be equipped with appropriate electrical and service nutlets and air conditioning. The estimated costs :.1clude the installation of cables that link the laboratory instruments with the computer.

\section{Spare Parts and Test Equipment}

To maintain the system, a minimum complement of spare parts and test equipment must be acquired. Spare parts should include items such as control logic cards, power supplies, operational amplifiers, relays. and connectors. The cost for a recommended quantity of these items is approximately $\$ 3,000$. The major testequipment item-an oscilloscope-will cost approximately $\$ 7,000$. Thus, approximately $\$ 10,000$ is estimated for both spare parts and test equipment.

\section{System Installation}

Based on previous installations, system-installation costs are estimated to be $\$ 37,000$. Costs include shipment of the system, installation at the Edison laboratory, hardware and software check-out, operational testing of the complete system, and training of personnel who will use the system.

\section{Instrument Interfaces}

For options 1 and 2, the existing interface designs from previous EPA installations are applicable to Region Il candidate instruments. For option 3, however, it will be necessary to redesign the general computer interface (digital bay, etc.). We anticipate that the Jaboratory instrument interface designs for the existing system will be applicable with the option 3 PDP.11 system.

Fabrication costs will be incurred equally for all three options. A summary of interface design and fabrication costs is given in Table B-2.

Table B-2. Summary of interface design and fabrication costs.

\begin{tabular}{lcc}
\hline \multicolumn{1}{c}{ Type of interface } & Options 1 \& 2 & Option 3 \\
\hline General interface design & - & $\$ 5,741$ \\
General interface fabrication & $\$ 9,300$ & 9,300 \\
Becknian 915 fabrication & 1,30 & 1,390 \\
Oceanographic intemational fabrication & 3,000 & 3,000 \\
Autofnalyzer 1I (4 units) fabrication & 16,200 & 16,200 \\
Atomic absorption PE 460 fabrikation & 1,300 & 1,300 \\
Atomic absorption PE 403 fabrication (2 units) & 2,600 & 2,600 \\
Metulor balance fabrication & 600 & 600 \\
Total cost & $\$ 34,300$ & $\$ 40,041$ \\
\hline
\end{tabular}

-Includes shared cost of a 36,000-BTU air conditioner required to supply conditioned air to several rooms, one of which is the proposed $330-\mathrm{ft}^{2}$ computer room. 


\section{Software}

For options 1 and 2, existing laboratory instruments applications programs developed for currently installed EPA automation systems are applicable to the Region 11 candidate instruments and quality control operations. However, for option 3, extensive modifications and debugging will have to be made to adapt the autonation software to a PDP-II system.

We estimate that rewriting the Assembly-language code for the operating system and the instrument programs (assembly language calls) will require approximately $50 \%$ of the eiffort to initially develop tht coding. We estimate that rewriting of the Basic-language applications programs will require approximaiely $35 \%$ of the initial effort to develop the programs. Table B-3 lists a breakdown of the soitware costs.

Table B-3. Cost of rewriting EPA software to operate on a digital equipment PDP-11 sy stem.

\begin{tabular}{lrr}
\hline \multicolumn{1}{c}{ Rewrite task } & Assembly-language code & Basic-language code \\
\hline Computer system programs & $\$ 41,000$ & - \\
Technicon AutoAnalyzer program & 12,000 & $\$ 30,000$ \\
Atomic absorption program & 7,000 & 21,000 \\
Metuler balance program & 3,500 & 6,500 \\
Beckman 915 program & 3,500 & 15,000 \\
Ocetanographic international program & $\$, 000$ & $\$ 5,000$ \\
\multicolumn{1}{c}{ Subtotals } & $\$ 7,000$ & $\$ 87,500$ \\
\multicolumn{1}{c}{ Total } & & $\$ 161,500$ \\
\hline
\end{tabular}

For options 2 and 3, additional software costs will be incurred to implement communications with the SFC system. For Region II, this is estimated to be approximately $\$ 20,000$, which represents only a small fraction of the total costs required to develop the entire laboratory management system. It is assumed that each EPA laboratory interested in developing a SFC system will budget a minimum of $\$ 20,000$ toward its development. The Office of Research and Development and the Management Information and Data Systems Division of the Office of Planning and Management are committed to fund a portion of the SFC development costs.

Table B-4 summarizes the software costs for the three proposed optional automation systems.

Table B-4. Summary of software costs for the three optional automation systems.

\begin{tabular}{lccc}
\hline \multicolumn{1}{c}{ Software } & Option 1 & Option 2 & Option 3 \\
\hline Instrument applications programs & No cost & No cost & $\$ 161,500$ \\
Communications with SFC & Not appl. & $\$ 20,000$ & 20,000 \\
\multicolumn{1}{c}{ Totals } & - & $\$ 20,000$ & $\$ 181,500$ \\
\hline
\end{tabular}




\section{APPENDIX C. DETAILED ASSESSMENT OF AUTOMATION BENEFITS}

To assess the benefits that will accrue to Region 11 as a result of automation, we compared the manualeffort (no automation) that will be required to meet the expected woikload (in the candidate instrumental analysis and sample coordination and management areas) to the effort we project will be reguired if automation is implemented. Effort here is defined as the time required for an employee to perform a task and is expressed as multiple or fractional full time employee (FTE), or both. We examined the detailed procedural tasks assuciated with the instrumental methods and sample management processes that are candidates for automation. For each candidate, only those tasks that can be fully or partially automated will be more effortefficient.

\section{Instrumental Methods}

We have adopted a model to calculate the effective time requi ed of a chemist to make a determination using any of the candidate instruments. The model takes into consideration the multiple tasks that he must make which includes factors for quality control samples, reruns, and samples that are diluted. With the effective time, and the number of determinations per year, one can calculate the total chemist time in effort (FTE) to handle the workload.

The model is used to calculate the effort required for a single determination using manual techniques vs automated techniques.

The following two equations are used in the model:

$$
t_{s}=p+(1+f)(w+i+c)+f d,
$$

where

$\mathrm{t}_{\mathrm{S}}=$ total chemist time needed for each determination,

$\mathrm{p}=$ tim. $\iota$ for preparation of sample and log book per determination,

$w=$ line needet to write log and introduce sample per determination,

$\mathrm{i}=$ chemist tinte spent in operating the instrument per determination,

$c=$ time needed to calculate and transcribe results per determination, and

$\mathrm{d}=$ time taken for a single dilution, and

$f=$ fraction of off-scale samples requiring dilution;

$$
\mathrm{e}=\mathrm{t}_{\mathrm{s}} \text { qr } \frac{\mathrm{HI}}{\mathrm{H}-\mathrm{T}_{\mathrm{v}}}
$$

where

$\mathrm{e}=$ the effective ehemist time taken per determination,

$q=$ quality assurance factor,

$r=$ retest factor (fraction of samples retested for reasons other than being off-scale),

$\mathrm{H}=$ time of a work session (this is the total average operator time spent for a work session), and

$T_{b}=$ time to set up instrument at the beginning of each work session, shut it down at the end, and run standards.

With the model, calculations of the benefits to be realized by automation of the candidate instrumental Inethods, quality-control procedures, and management taiks are given in the following sections.

\section{Technicon Autodnalyzes}

It is projected that in two years, approximately 6000 determinations/y will be performed by the Technicon AutoA nalyzer. In Table C-1 we give a breakdown of the tasks involved in the method and a comparison of the effort that will be required for the present methods vs automated methods. 
Table C-1. Technicon AutoAnalyzer.

Description of the task-times and time factors

Symbol

At present

- ith automarion

Preparation of the sample

Write log, introduce sample

Operation of instrument by chemist

Calculation and transeription of results

Dilution of one off-scale sample

Factor for samples diluted

Calculated chemist time/detemination

Retest factor

Quality-control ractor

Setup and shutdown houts per: work session

Hours per work session

Calculated effective chemist time

per determination

Benefit calculations

Number of determinations/chemist-day

Determinations/y (projected)

Chemist-days/y to meet load

Chemist-days/y (av)

Chemist-years (FTE) to meet load

Effort efficiency $=2.32+1.19=1.13$ FTE i

$t_{B}$

r

$\mathbf{q}$

$\mathbf{T}_{\mathbf{b}}$

e
65 min

1.4. $\mathrm{min}$

$2.2 \mathrm{~min}$

$4.4 \mathrm{~min}$

5.0 min

0.15

$19.4 \mathrm{~min}$

1.05

1.5

1.75

6.5

$4: .8 \mathrm{~min}$

$21.4 \mathrm{~min}$
$6.0 \mathrm{~min}$

$1.5 \mathrm{~min}$

$2.2 \min$

$1 \mathrm{~min}$

$5.0 \mathrm{~min}$

0.07

$10.3 \mathrm{~min}$

1.01

1.5

1.75

6.5

$\begin{array}{cc}11.5 & 22.4 \\ 6000 & 6000 \\ 522 & 268 \\ 225 & 225 \\ 2.32 & -1.19\end{array}$

\section{Atomic Absorption Spectrophotometers}

It is projected that approximately 7000 determinations/y will be made using the atomic absorption spectrophotometric method. Table $\mathrm{C}-2$ gives a breakdown of the tasks involved in the method and a comparison of the effort that will be required for the: present methods vs automated methods.

\section{Total Organic Carbon}

It is projected that approximately 1000 deten ninations/y will be performed by the Bechman 915 Total Carbon method. Table C-3 lists the tasks involved in the method and a comparison of the effort that will be required for the present methods vs automated methods.

\section{Total Organic Carhon}

It is projected ti at approximately 1000 determinations/y will be performed by the Oceanographic International total carbon methods. Table $C-4$ gives a breakdown of the tasks involved in the method and a conparison of the effort that wall be required for the present methods vs automated methods.

\section{Electronic Balance}

It is projected that approximately 2000 determinations/y (approximately 6000 weighings) will be made on the electronic balance. Table C-5 gives a breakdown of the tasks involved in the method and a comparison of the effort that will be required for present methods vs automated methods.

\section{Quality Control}

During 1976, approximately 1.25 FTE of the operations and review (O\&R) personnel was devoted to control compliance. In Table C- 6 we show a breakdown of the tasks and compare the present effort to that projected after automation. 
Table C-2. Atomic Absorption.

Description of the task-times and time factors

Symbol

At present

With rotomation

Preparation of the sample

Writelog, introduce sample

Operation of instrum? nt by chemist

Calculation and transcription of resules

Dilution of one off-scale sample

Factor for samples diluted

Cajculated chemist time/detemination

Retest factor

Quality-control factor

Setup and siutdown bours per work session

Hours per work session

Calculated effective chemist time

per determination

Benefit calculations

Number of determinations/chemist-day

Deteminations/y (projected)

Chemist-days/y to meet load.

Chiemist-days/y (av)

Chemist-years (FTE) to meet load

Efrort efficiency $=1.28-0.92=0.36 \mathrm{FTE}$

\section{$3.9 \mathrm{~min}$}

$1.0 \mathrm{~min}$

$2.0 \mathrm{~min}$

2.0 min

$5.0 \mathrm{mir}$

$0.1 \mathrm{~min}$

$9.9 \mathrm{~min}$

1.02

1.8

0.5

5.5

$\begin{array}{ll}\mathrm{T}_{\mathrm{b}} & \mathrm{G.5} \\ \mathrm{H} & \end{array}$

$19.7 \mathrm{~min}$
$14.3 \mathrm{~min}$

3.9 min

$0.5 \mathrm{~min}$

$2.0 \mathrm{~min}$

0 min

$5.0 \mathrm{~min}$

0.1 min

$7.2 \mathrm{~min}$

1.02

1.8

0.5

6.5

0.92

Table C-3, Beckman 915.

Description of tho: task-times and time factors

Symbod

At present

With automation

Preparation of the sample

Write $\log _{\text {, introducu sample }}$

Operation of instrument by chemist

Calculation and transcription of results

Dilution of one off-scale sample

Factor for samples diluted

Calculated chemist time/detormination

Relest factor

Quality-control festor

Setup and shutdown hours per work session

Hours per work session.

Calculated effective chemist time

per determination

Benefit calculation

Number of deternitnations/chenist-day

Determinations/y (projected)

Chemist+4ays/y to meet load

Chemist-days/y (av)

Chemist-yeari (FTE) 10 meet load

Effort efficiency $=0.580 .44=0.14$ FTE

\section{p}

w

i

c

d

f

ts

r.

$\mathbf{q}$

$\mathbf{T}_{\mathbf{b}}$

H

7.7

1000

130

225

0.58

0.1

3.I
5.0 min

$2.0 \mathrm{~min}$

$12.0 \mathrm{~min}$

o min

$5.0 \mathrm{~min}$

5.0 min

0.1

$20.9 \mathrm{~min}$

1.01 .

1.01

1.8

0.6

3.1

$47 \mathrm{~min}$

10.2

1000

98

225

0.44 
Table C-4. Oceanographic International.

Description of the task-times and time factors

Symbol

At present

With automation

Preparation of the sample

Write log, introduce sample

Operation of instrument by chemist

Calculation and transcription of tesults

Dilution of one off-scale sample

Factor for samples diluted

Calculated chemist time/determination

Retest factor

Quality-control factor

Setup and shutdown hours per work session

Hours per work session

Calculated effective chemist time

per determination

Beneft calculations

Number of determinations/chemist-day

Determinations/y (projected)

Chemist-days/y to meet lond

Chemist-days/y (av)

Chemist-years (FTE) to meet load

Effort efficiency $=\mathbf{0 . 6 6 - 0 . 5 5}=0.11$ FTE

$\begin{array}{lrrr}\text { p } & 12.0 \mathrm{~min} & 12.0 \mathrm{~min} \\ \text { w } & 6.0 \mathrm{~min} & 2.0 \mathrm{~min} \\ \text { i } & 12.0 \mathrm{~min} & 12.0 \mathrm{~min} \\ \text { c } & 6.0 \mathrm{~min} & 0 & \mathrm{~min} \\ \text { d } & 5.0 \mathrm{~min} & 5.0 \mathrm{~min} \\ \text { f } & 0.1 \mathrm{~min} & 0.1 \mathrm{~min} \\ \text { t } & 34.5 \mathrm{~min} & 28.0 \mathrm{~min} \\ \text { r } & 1.01 & 1.01 \\ \text { q } & 1.8 & 1.8 & \\ \mathrm{~T}_{\text {b }} & 0.6 & 0.6 & \\ \text { H } & 4.6 & 4.6 & \end{array}$

e

$72 \quad$ min

$59 \quad \mathrm{~min}$

6.7

8.1

10001000

149

225

0.66

Table C-5. Electronic balance.

Description of the task-times and time factor

Symbol

At present

With automation

Preparation of the sample

Write $\mathrm{log}$, introduce sample

Opestion of instrument by chemist

Calculation and transcription of results

Ditution of one off-scale sample

Factor for mples diluted

Calculated chemist time/determination

Retest factor

Quality-conitrol factor

Setup and hutdown hours per work sexion

Hours per work session

$$
\text { i }
$$

Calculated effective chemist time per determination

e

e

Benefit celculations

Number of determinations/chemist-day.

Determinations/y (projected)

Chemist-daysty to meet lond

$\mathbf{T}_{\mathbf{b}}$

Chemist-day/y (av)

Chemist-years (PTE) to meet losd

Effort efficiency $=0.40-0.29=0.11$ FTE

$21.5 \min$

$15.9 \mathrm{~min}$

$16.4 \mathrm{~min}$

12.1 min

2000

1.02

1.02

1.2

1.2

0.2

0.2

7.5

7.5

$10.0 \mathrm{~min}$

$1.0 \mathrm{~min}$

$1.1 \mathrm{~min}$

0 min

$-$

225

0.40
30.2

2000

66.2

225

0.29 
Table C-6. Quality control.

\begin{tabular}{|c|c|c|}
\hline Task: & $\begin{array}{l}\text { Quality contrcl } \\
\text { at present, FTE }\end{array}$ & $\begin{array}{l}\text { Quality control } \\
\text { with sutoniation, FTE }\end{array}$ \\
\hline Statistical sclestion and calculation of Shewlert criteria & 0.85 & $\mathbf{0 , 2 0}$ \\
\hline Review of sample results for compliance to Shewhan limits & $\mathbf{0 . 4 0}$ & $\mathbf{0 , 1 0}$ \\
\hline Totals & 1.25 & 0.30 \\
\hline Effort efficiency $=1.25-0.3=0.95$ FTE & & \\
\hline
\end{tabular}

\section{Sample Management Tasks}

Administration and supervisory duties, coordination of studies, data collation, and summary analyses reports are considered masagement tasks. In this study, we are concerned with those tasks that relate directly to operations of the analytical laboratory and the report of analyses. Our purpose in this study is to determine what part of the general management effort is related to analyses reports, which tasks can be automated, and the benefits to be accrued.

During 1976, the management efiort of the Technical Support branch was determined to be 2.6 FTE; this included $10 \%$ of the branch supervisor and $50 \%$ of a secretary, $50 \%$ and $20 \%$ of the time of two section supervisors, $80 \%$ of a sample-receiving and $\log$-in (OSCAR) employees, and $5 \%$ of the time from ten laboratory analysts.

Table C-7 shows a breakdown of the management tasks and a comparison of the present efiort expended relative to the effort projected after automation.

Table C-7. Management tasks.

\begin{tabular}{|c|c|c|}
\hline Tasks & $\begin{array}{l}\text { Present } \\
\text { effort, } \\
\text { FTE }\end{array}$ & $\begin{array}{c}\text { Elfort } \\
\text { with automation, } \\
\text { FTE }\end{array}$ \\
\hline Setting up new studies & 0.10 & 0.05 \\
\hline Determining the status of atudles & 0.20 & 0.04 \\
\hline Collating data on samples (OSCAR) & 0.60 & 0.10 \\
\hline $\begin{array}{l}\text { Coordinating priorities relntive to concurrent } \\
\text { studies, workload, etc. (OSCAR) }\end{array}$ & 0.10 & 0.05 \\
\hline $\begin{array}{l}\text { Handling requests and implementing changes } \\
\text { in st:dy plans (OSCAR) }\end{array}$ & 0.10 & 0.01 \\
\hline Checking summary analyeesa & 0.80 & 0.15 \\
\hline Managing branch activities, personnel, flnances, etc. & 0.20 & 0.20 \\
\hline Typing relative to andysis datz & 0.50 & - \\
\hline Total & 2.60 & 0.60 \\
\hline EfPort efficiency $=2.6-0.6=2.0 \mathrm{FTE}$ & & \\
\hline
\end{tabular}

Apart of the FTE effort in this category is related to quality-sontrol dath 
Table C-8. Summary of automation benefits.

Candidate ares for sutomation

Automation of instruments

Technicon AutoAnalyzers

1.13

Atomic absorption spectmphotometry

Dectronic balance

Tolat carbon anslyzers

Subtotal

2.41

Automation of quality control

0.95

Autometion of sample management

2.00

Totn 


\section{APPENDIX D. BREAKDOWN OF ADDED OPERATING COSTS FROM AUTOMATION}

The three proposed optional automation systems each will add new costs to the annual operating costs of the laboratory. Included will be maintenance of the computer hardware and peripherals, the laboratory instrument hardware interfaces, and the software associated with the automated instruments. Also, for those options that include communications with a SFC system, there will be additional costs for maintenance of the added computer hardware, software, and telephone communications.

New skills and capabilities will clearly be required by Region II to implement ad maintain an efficient automation system. The Environmental Research Center (ERC) in Cincinnati, through its experience with laboratory automation, has summarized these requirements (see Appendix E). D-1.

The annual operating costs that reflect the above requirements for the three options are listed in Table

Table D-1. Annual operating costs for three options of the proposed laboratory automation system.

Operating cost category

Maintenance of the computer hardware and peripherals (vender supplied) ${ }^{\mathbf{a}}$

In-housc maintenance of interface hardware and software (including communications with $\mathrm{SFC}^{\mathrm{C}}$ for options 2 and 3 )

Total

a Estimated to be equivalent to $12 \%$ of the cost of the computer and poripherals.

bApproximately one-hulf of a full time employee's time (0.5 FTE) with the skills described in Appendix E is recommended.

${ }_{A}$ A total of one full-tima employee (PTE) with the skills described in Appendix $E$ is reconimended. The additional 0.5 FTE relative to options 1 and 2 is required for maintenance of communications with SFC. 


\title{
APPENDIX E. NEW PERSONNEL SKILLS AND CAPABILITIES RECOMMENDED FOR THE AUTOMATED LABORATORY
}

\author{
Bruce P. Almich \\ Environmental Research Center (ERC) \\ Cincinnati, Ohio
}

Our purpose in this appendix is to describe the management of a prospective automated client laboratory: a concise description of the new skills and capabilities required to plan and implement the processes of training, manpower allocation, and (if necessary) hiring before the system is installed. This appendix is also designed to serve as an operational-policy basis for client-ERC-LLL-vendor relationships.

The new functions and responsibilities required in an automated laboratory are divided into two broad activities related to: (1) laboratory use, and (2) computer-system maintenance. The two activities require different personnel skills and capabilities. Within the laboratory, the following subdivisions exist.

1. The system is used as a means of processing analytical samples; for example, conducting a dialogue with the computer as it executes instrument-control, data-acquisition, and manipul tion programs.

2. Programs are modified, as required, to tailor them to specific laboratory needs. Modifications by the laboratory scientist are limited to changes in the basic programs, such as report format output, and data-reduction procedures.

For computer maintenance, the following subdivisions exist.

1. Hardware maintenance and upgrades. This includes handling the vendor's computer service contract, as well as taking responsibility for maintaining the custom electronics hardware. Details of these skills are described below.

2. Instrument control and applicalions software maintenance and upgrades (if any). This includes assisting the laboratory scientist in making changes in the basic programs.

The first broad-skills area is associated with the daily use of the system by the laboratory scientist. To use an automated laboratory system, the laboratory scientist must interact with the computer. He accomplishes this at the typewriter terminal located near the instrument by entering data and control information in response to computer queries and prompts. The scientist must modify his previous analytical procedures and methods somewhat to accommodate this new man-machine dialogue. He should be aware of what corrective actions are nccessary when an error occurs; for example, he types in the wrong command, injects the wrong sample. or the computer detects or causes an error. As the laboratory scientist becomes more familiar with the system during the first two months of operation, he should be able to spot and correct human, instrument, or computer malfunctions quickly and be able to report the symptoms of more involved problems to the systemmaintenance person for action. These direct-system skills are acquired by the laboratory scientist in four ways.

1. Working visits can be made to ERC/Cincinnati for instruction before delivery of the system. This includes observation and use of a similar automated instrument or procedure by the prospective new client under the guidance of a scientist skilled in using the new equipment.

2. An existing laboratory system computer can be remotely accessed from a dial-up terminal for learning the basic language and instrument program dialogues before the system is delivered at the client's site.

3. The automation-installation team can tutor scientists at the client's site during system installation.

4. Self-study operation manuals for each instrument and facility can be provided with the system.

As the laboratory scientist becomes more familiar with the use of his automated instrument, he will probably want to modify and extend the capabilities of the Basic applications software as follows.

1. Streamline the instrument setup and operation dialogue once he has gained familiarity with the inputs needed for the system to carry out his analyses. (For example, shorten ENTER NUMBER OF SPIKED SAMPLES to SPIKES?)

2. Convert runtime options (provided with the delivered system) to program constants to save time in the event that the inputs would not need to be changed during a normal future run. (For example: remove variable input prompt SPIKES? and convert it to a program constant.) 
3. Change the instrument data-reduction algorithm to accommodate a special data-analysis requirement or to implement a new analysis method.

4. Change the structure, content, or appearance of an output report.

To accomplish this, the scientist must spend time in learning additional details of the Basic-language interpreter and the structure and operation of the currently implemented Basic program for his instrument. The depth of $\mathrm{kn}$ uvledge required in these areas is dependent on the degree of program modification desired; informal coursework and self-study are required. The analyst should also learn how to document the programming changes he makes in the Basic code. He should make every effori to keep current and accurate the documentation for the automated operation of his instrument. If the anafyst substantially modifies the diskfile or the logic structure from that of the delivered system, he should assume responsibility for the local software support. The scientist also assumes responsibility for local post-delivery modifications to the sample file control interface so that one agency-wide SFC may exist in the future.

The first broad-skills area thus represents a reallocation of existing laboratory efforts and skills to use the automated system effectively. Each analyst must learn new skills to interact with the computer in making laboratory analyses. For elementary skills, no programming training or knowledge is required. To modify the delivered package of Basic-language software to meet post-delivery requirements, the scientist must acquire programming skills in Basic language. Basic is the simplest, most lexible, and general language available; it is lypically taught to high school students in mathematics classes and is required study for most technical undergraduate and graduate university degree programs. Cumulative experience within EPA indicates that the dialogues between instruments are easily learned. Modification and enhancement of the delivered Basic programs by EPA Laboratory personnel is also being accomplished in-house, albei: at a fairly low level at present. Table E- $\mathrm{I}$ summarizes this discussion of the estimated resource requirements that must be met for raining personnel in the first broad-skills area.

Table E-1. Estimated resource requirements for training personnel in the automated labc:atory.

Training steps

Time/resources required

Leaming how to use the system as delivered

(tutorinl course given at installation time)

Learning how to spot and correct malfunctions

Predelivery orientation (by dial-up terminal or visits to ERC/Cincinnti)

Introductory course/study in Basic a

Advanced topics in Basic (required for extensive program modiffcations)

Tralning or self study in program structure ${ }^{a}$ (making full use of the system)

\section{One-man-wk/analyst}

One-man-wk/instructor

First two months of use

Threc-man-days/analyst

Onc-man-wk/analyst

One-man-wk/instructor

One-man-wk/analyst

One-man-wk/instructor

Learned during first nine months of operation by motivated users

aptional

The second broad-skills area is associated with the maintenance of the overall laboratory automation system as a collection of hardware and software elements including instruments, interfaces, computers, and programs. We define "in-house maintenance person" as a person who has all the skills and capabilities required in this area, although these skills may be either concentrated in one or two people or shared among several in the laboratory. The hardware and software classes are shown in Table E-2 for reference to the following discussion. 
Table E-2. Hardware and software classes.

Classes of software:

System: NOVA/ECLIPSE Assembly language, vendor supplied (Data General Corp.), and LLL/EPAdeveloped.

Applications: standard high-level languages, Basic interpreter code for instrument automation, and data reduction.

Classes of hardware:

Computer (maintained under service contract at a cost of $\$ 1 \mathrm{~K} / \mathrm{mo}$ ).

Custom (LLL/EPA-designed and developed) includes terminals, cables, connectors, instrument interfaces, computer interfaces, etc.

Lab instruments (e.g. Technicon AutoAnalyzer, Perkin/Elmer AA spectrophotometer, etc.)

With these classes and the four functional-maintenance subdivisions listed at the beginning of this appendix, the maintenance activity can now be defined.

The primary responsibility of the maintenance person is to keep the hardware and software system in working order by preventive and remedial maintenance and by installing improved and extended hardware and software (upgrades) as required. Preventive maintenance is required to minimize the frequency, losses, and restoration costs of unforeseen breakage whereas remedial maintenance is required when something breaks down.

For preventive maintenance, the main responsibilities are as follows.

1. Monitor the computer hardware maintenance contract and assure that the computer receives its monthly preventive maintenance service from Data General, as provided in the contract. Keep Data General appraised of problem areas with the equipment.

2. Periodic inspection (e.g., offline testing and observing production) of the custom and lab instrument hardware to assure correct operation.

3. Periodic backups and library maintenance of all software disk files. Backups should be made in triplicate on magnetic tape, with an indexing system for locating disk-file images on the tape. A. backup should be made of the affected program and data files whenever a net investment (or replacement cost) of effort in these files exceeds an average of four hours of work per laboratory analyst or computer programnier.

The in-house remedial maintenance skills required are those needed to successfully complete the following sequence of tasks whenever equipment breaks down.

1. Identify the symptoms of the problem to ascertain which instruments, users, and system functions are affected.

2. Isolate the problem to the subsystem level; for example, to one of the three types of hardware in the system.

3. If the problem is in a laboratory instrument, initiate repairs in-house, by contract, or by outside outof-contract repairs. (It is importani to keep a iministrative delays to a minimum when procuring service with established, reputable organizations.)

4. If the problem is in the custom EPA/LLL hardware, initiate in-house repairs. Begin by replacing electronic spare parts. The client lab should have a complete set of replaceable parts for all custom hardware on site; this is recommended to all clients who do not have ready access to a large supply of electronics and mechanical hardware. If difficulty is encountered, assistance may come from another client such as ERC/Cincinnati, or eventually from LLL through ERC. If requested, ERC will provide a list of recommended tools and troubleshooting/repair equipment.

5. If the problem is in the computer, two determinations must be made:

- The problem must be identified in either the hardware or software.

- The problem must be identified as a "Data-General" problem or "non-data-General" problem. Carelessness hire can result in a prematuse commitment to expensive out-of-contract vendor service.

Carelessness here can result in a premature commitment to expensive out-of-contract vendor service. Generally, if the problem is in the computer hardware and present when Data-General diagnostic or unmodified system software is sunning (with the $Z Z L$ custom hardware-interface board removed), Data General may be called in for free in-contract repairs. If the problem is in the agency-wide supported version of the 
operational software, a second client lab or ERC may be called for immediate consultation or assistance if necessary. If no local resources are available, all other problems must be handled individually, with the primary repair responsibility placed on the client lab and its local resources. In-house hardware repairs and modifications should not be made on Data-General hardware. Other electronic repairs should be made at the module or board-replacement level. Purchase of electronic diagnostic and replacement equipment is at the client's discretion, but ERC/Cincinnati will consult with the client if requested. A list of parts and their availability for custom electronic and mechanical hardware should be kept current. Thc maintenance policy for EPA lab automation is:

i. Agency-wide support-all support external to the client laboratory-is available for all hardware and software as delivered and put in operation by the installation team and for all agency-wide-supported upgrades.

2. Depending on the nature and extent of local post-installation modifications to the delivered system and adherence to agency-wide system improvements, post-delivery support from all sources external to the client laboratory will vary. Generally, if you change a system, you must support that change even if the person who changes it leaves; undocumented changes cannot be supported by anyone. The Data-General service contract with GSA is a good reference in this area.

Another maintenance person's responsibility is to assist the laboratory staff in making necessary workable changes and additions to the delivered package of applications software. At present, this is limited to the basic instrument programs and communications with the sample file-control system. During system operation the maintenance person has historically assumed the role of instructor and consultant to the laboratory scientist. He accomplishes this by completing the training steps described in Table E-1.

The remaining responsibility for maintenance personnel is installing and testing hardware ar. $\mathrm{J}$ software upgrades in one of the following circumstances.

1. If the client lab determines that it has a need for additional hardware or software that is not on the agency-wide support list, the la's can take responsibility for designing, obtaining approval for, and implementing a new facility. This can be involved and complex, especially for software modification and when obtaining headquarter approvals.

2. If a proposed upgrade is to be applicable agency-wide, external support can be obtained for its implementation. Here, a system is designed, approvals are secured. and the implementation is accomplished with the assistance of ERC/Cincinnati. This is the preferred procedure for adding a new instrument to the system. An example of this is the agency-wide maintenance of the Data General systems-software subscription service, distributed by ERC/Cincinnati and installed where needed in all laboratory automation sites.

Some of the systems-level upgrades are required to be made on all machines to extend performance, fix system bugs, and assure that applications software can be transported. This is easily accomplished at the client site because the skills required are only those using the Data General operating system command language and the text editor. More complicated software upgrades may be handled by directly loading a client computer with operating software via telecommunictions with the ERC/Cincinnati facilities.

How will the maintenance person be trained to provide the services to the laboratory in t'.e second broadskills a rea? The following ideas on this training requirement were gained from agency-wide experience to date.

- With the purchase of a Data General computer system, the customer is entitled to a limited number of free training credits (two man-weeks) at one of two Data General training centers in the U.S. Before the system is delivered, two to four man-weeks of training must be completed, preferably by two laboratory pcople. Each person should train for one week in Data-General operating system concepts and facilities and one week in either Assembly or Fortran programıning, or hardware-maintenance overview. It is desirable for two people to pursue this study for each laboratory for the laboratory to realize service continuity if the trained maintenance person is absent or changes jobs.

- Each maintenance person should spend a minimum of one week at predelivery orientation training in a working laboratory elsewhere in ihe agency. Five to eight working days at ERC/Cincinnati would be optimum.

- Each maintenance person should participate in the installation and delivery testing phase after receiving training from 1 and 2 above and train an additional week at delivery time from the installation team members.

- Approximately six months of post-delivery operation from time will be required for the maintenance persca to become proficient in his duties. 
In conclusion, we have provided the prospective client laboratory with a description of the pcrsonnel skills required for the proper use of a laboratory automation system, by describing two broad areas of functions and responsibilities. The first area, associated with a reallocation of existing personnel skills within the laboratory; the second area, associated with maintenance of the automated laboratory, can be staffed in one of the following ways.

- One or two existing laboratory people can be trained and reassigned 40 perform the tasks with no additional personnel required. These people could be selected from chemists with some computer background, or from an existing in-house person with electronics and some high-level language programming background. This would be especially appropriate in an established small-to mediumsized laboratory with modest modification needs.

- A new chemist or electronics technician with some previous computer background could be hired. Background in electronic equipment service and iepair and Basic/Fortrau programming is valuable, This is the most appropriate course of action for large-production laboratories that are interested in proper system use and upgrades.

- The persons described above could be combined to form a working team of principal-automation chemist and system-maintenance person, a desirable team for a laboratory engaged in large-volume sample testing and having the capability for significant system improvements.

- Personnel described above could be combined with a computer programmer with primary emphasis on software maintenance and improvements. Hardware could be maintained with additional outside assistance.

With these alternatives, it is estimated that the first broad-skills area should require no new hiring. The second area of skills minimumly requires no new hiring in a laboratory with few plans for system improvements and one containing well-motivated chemists with prior computer science backgrounds. Most likely, one new chemist or engineer-technician would be hired for minimum support of 0.5 man-years/year by the maintenance person. The maximum new personnel requirement would be 2 man-years/year, resulting in full inhouse hardware, instrument/SFC software support, maintenance, and upgrades. In this cost-benefit analysis 1 man-year/year has been allocated for proper functioning of the recommended automated system. 